\title{
On-machine measurement method for dynamic stiffness of thin-walled workpieces
}

$\operatorname{AUTHOR}(S)$ :

Kono, Daisuke; Umezu, Takuma

\section{CITATION:}

Kono, Daisuke ... [et al]. On-machine measurement method for dynamic stiffness of thin-walled workpieces. Precision Engineering 2019, 60: 299305

ISSUE DATE:

2019-11

URL:

http://hdl.handle.net/2433/244288

\section{RIGHT:}

(c) 2019. This manuscript version is made available under the CC-BY-NC-ND 4.0 license

http://creativecommons.org/licenses/by-nc-nd/4.0/.; The full-text file will be made open to the public on 1 Novembe 2021 in accordance with publisher's 'Terms and Conditions for Self-Archiving'.; この論文は出版社版でありません。引 用の際には出版社版をご確認ご利用ください。; This is not the published version. Please cite only the published version. 


\title{
On-machine measurement method for dynamic stiffness of thin-walled workpieces
}

\author{
Daisuke Kono ${ }^{1}$, Takuma Umezu ${ }^{1}$ \\ Corresponding author: Daisuke Kono \\ ${ }^{1}$ Department of Micro Engineering, Graduate School of Engineering, Kyoto University, \\ c1S09, C3,Kyotodaigaku Katsura, Nisikyo-ku, Kyoto 615-8540, Japan \\ Email: kono@prec.kyoto-u.ac.jp \\ Phone: +81-75-383-3676 \\ Fax: +81-75-383-3676
}

\begin{abstract}
This paper proposes a novel measurement method for the dynamic stiffness of thin-walled workpieces. The proposed method is called the displacement sensorless piezoexcitation (DSPE) method. The DSPE method uses a piezoelectric shaker attached to a machine tool spindle. Sensor setup on workpieces is not required because workpiece displacement is estimated from the excitation force and input voltage to the shaker. A measurement instrument based on the DSPE method was developed. The measurement accuracy of the DSPE method was verified by comparing its measurement results to those of a conventional piezoexcitation method and impact tests. The experimental results demonstrate that the DSPE method is almost comparable to the conventional methods. Cutting experiments were conducted to analyze the workpiece compliance measured by the DSPE method and the vibration amplitude during cutting. The results demonstrate that the DSPE method can accurately evaluate the dynamic stiffness affecting vibration during the cutting process.
\end{abstract}

\section{Keywords:}

on-machine measurement, dynamic stiffness, thin-walled workpiece, piezoelectric shaker, sensorless 


\section{Introduction}

Machining thin-walled workpieces has recently become a popular topic in the manufacturing field [1-3]. In particular, the aerospace industry demands high productivity for such machining. The vibration of workpieces is a crucial issue because it limits the productivity and accuracy of machining processes. Machining conditions must be set based on the dynamic stiffness of workpieces. Therefore, the dynamic stiffness measurement of workpieces is an important task.

Thin-walled workpieces are typically supported by fixtures to suppress vibration during machining. Novel fixture systems using polymers and magnetorheological fluids have been proposed to provide vibration damping [4-6]. Special robots can also be used to provide mobile support [7]. Evaluation of the effects of these fixtures is an important task for preventing failures during the machining process. Additionally, the dynamic stiffness of a workpiece can change because workpiece thickness is reduced as the machining process proceeds from roughing to finishing. Therefore, dynamic stiffness should be measured several times between processes. An automated on-machine measurement system for dynamic stiffness is essential for such frequent measurements.

Dynamic stiffness measurement of a workpiece has traditionally been conducted through excitation tests using shakers and impulse hammers. Electromagnetic shakers are used to provide random and sinusoidal excitations [8-10]. Although this excitation energy is greater than that provided by impulse hammers, shaker setup is more time consuming. Extra space for shaker setup is also required. Piezoelectric shakers can solve the space issue because they are relatively compact [11].

Impact testing using impulse hammers is a common practice for measuring dynamic stiffness [12, 13]. Impact testing is particularly popular for the dynamic stiffness evaluation of thin-walled workpieces because it is fast and simple [14-17]. However, impact testing has uncertainty depending on operator skill. In particular, measurement error caused by double hits can occur easily for low-stiffness objects, such as thin-walled workpieces. An automated impact excitation system has been developed using a solenoid to solve this problem [18].

In conventional methods, the excitation force and resultant displacement of a workpiece must be measured to obtain a dynamic stiffness value. Accelerometers are placed on a workpiece to obtain displacement measurements in most cases. Sensor setup on a workpiece is a difficult task in the development of an automated measurement system.

This paper proposes an on-machine measurement method for the dynamic stiffness of thin-walled workpieces. The proposed method uses a piezoelectric shaker attached to a machine tool spindle. Sensor setup on a workpiece is not required because the proposed method does not use sensors, such as accelerometers, to measure workpiece displacement. The proposed method is called the displacement sensorless piezoexcitation (DSPE) method. We also developed a measurement instrument based on the DSPE method. Its measurement accuracy was verified by comparing the DSPE method to conventional excitation tests.

The on-machine measurement of the dynamic stiffness of thin-walled workpieces using the conventional shaker method has been studied in our previous work [19]. The previous work investigated the influence of the shaker mass on measurement result. The development of the automated on-machine measurement system and the machining 
process based on the developed system will be presented in another publication. This paper focuses on the DSPE method and investigates its validity.

\section{DSPE method}

\subsection{Fundamentals of DSPE method}

Figure 1 presents a schematic of the excitation testing of a thin-walled workpiece. Fig. 1(a) presents a conventional excitation test using a shaker. The shaker is attached to the spindle of a machine tool by a tool holder. The shaker consists of a piezoelectric actuator and force sensor. The workpiece is excited by the shaker and the excitation force is measured by the force sensor. The resultant workpiece displacement is measured by an accelerometer attached to the workpiece. Dynamic stiffness is obtained in the frequency domain based on the measured force and displacement. This method is referred to as the piezoexcitation (PE) method for the remainder of this paper.

In the PE method, excitation can be automatically applied if excitation commands are synchronized with the computer numerical control of the machine tool. The excitation point can be selected flexibly based on the positioning of the machine. However, automatic sensor setup on a workpiece is difficult. However, it should be possible if accelerometers can be attached by external robots. Another possible solution is the use of a displacement sensor attached to the shaker. However, such solutions are not practical because workspace and measurement points are limited. A real workpiece has complicated shapes, such as ribs, slots, and holes. The fixture system for a workpiece also reduces the available workspace.

This paper proposes the DSPE method presented in Fig. 1(b). Excitation and force measurement in the DSPE method are similar to those in PE method. Workpiece displacement is estimated from the displacement of a piezoelectric actuator. In the DSPE method, workpiece stiffness is assumed to be much lower than that of the spindle, shaker, and tool holder. A certain preload is placed on the piezoelectric actuator to maintain contact between the workpiece and actuator. Under these conditions, workpiece displacement is equal to the displacement of the piezoelectric actuator. The displacement of the piezoelectric actuator is estimated from the excitation force and input voltage, as described in Section 2.2.

In the DSPE method, sensor setup on a workpiece is not required. Currently, the shaker must be attached to the machine tool spindle manually to handle the cables for the piezoelectric actuator and force sensor. Automatic attachment of the shaker by an

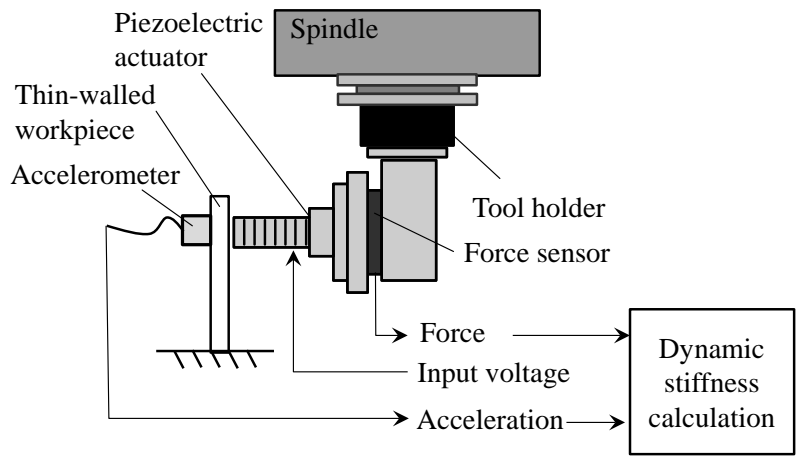

(a) PE method

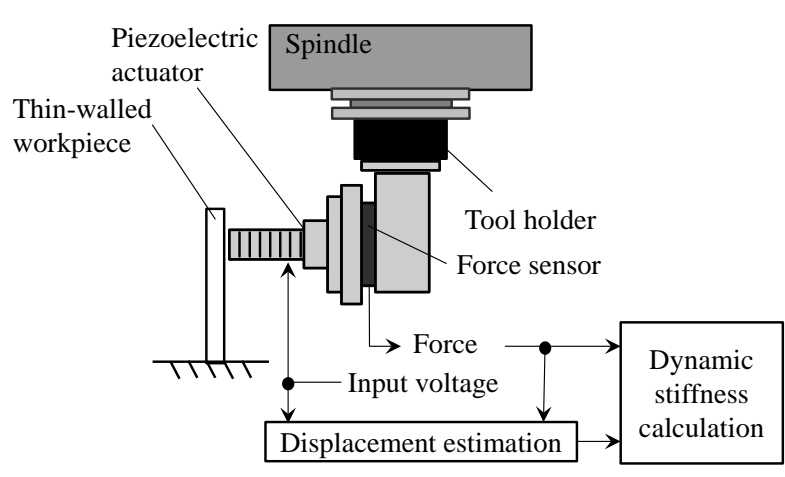

(b) DSPE method

Fig. 1 Measurement methods for workpiece dynamic stiffness 


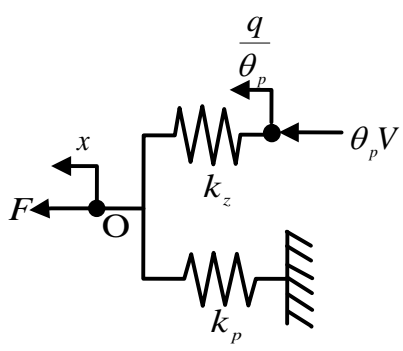

Fig. 2 Equivalent mechanical model of the piezoelectric actuator

automatic tool changer should be possible when the piezoelectric actuator and force sensor become wireless in future, allowing complete automatic stiffness measurement to be performed between machining processes.

\subsection{Displacement model of piezoelectric actuator}

In the DSPE method, workpiece displacement is estimated based on the displacement of a piezoelectric actuator. A displacement model for a piezoelectric actuator is described in this section. Fig. 2 presents the equivalent model of a piezoelectric actuator proposed by Yamada et al. [20]. Point $O$ is the tip of the piezoelectric actuator; $F$ is the reaction force under excitation, $x$ is the displacement of point $\mathrm{O}, k_{p}$ and $k_{z}$ are the mechanical and electrical stiffness of the piezoelectric actuator, respectively, $\theta_{p}$ is the elemental electromechanical coupling coefficient, which is the transformation coefficient between electric energy and mechanical energy, $V$ is the input voltage, and $q$ is the charge. The force generated by the piezoelectric actuator is expressed as $\theta_{p} V$. The equation for equilibrium at point $\mathrm{O}$ is written as follows:

$$
F=k_{p} x-\theta_{p} V \text {. }
$$

The displacement $x$ is obtained by the following equation:

$$
x=\frac{1}{k_{p}}\left(F+\theta_{p} V\right) .
$$

Therefore, the displacement of the piezoelectric actuator is derived from the $V$ and $F$ values measured during excitation.

\section{Excitation experiment}

The dynamic stiffness of a thin-walled workpiece was measured using the DSPE method. The measurement results were compared to the results of the conventional PE method and impact testing results to verify the measurement accuracy of the DSPE method. Strictly, the dynamic stiffness measured by impact testing may be different from that by DSPE and PE methods because the shaker contacts the workpiece in the DSPE and PE methods. The impact testing is used for comparison because it is the unique practical method for dynamic stiffness evaluation.

\subsection{Experimental method}

Figure 3 presents the experimental setup. A medium size vertical machining center was used in the experiment. The shaker described in Section 2.1 was attached to the spindle. Figure 4 presents a schematic of the piezoelectric actuator used in this experiment. Because the tip of the actuator is a small half sphere, the actuator contacts the workpiece at a single point. A thin-walled plate of carbon steel (JIS S50C) was used for the workpiece. An accelerometer (PCB Piezotronics) was attached to the workpiece. 


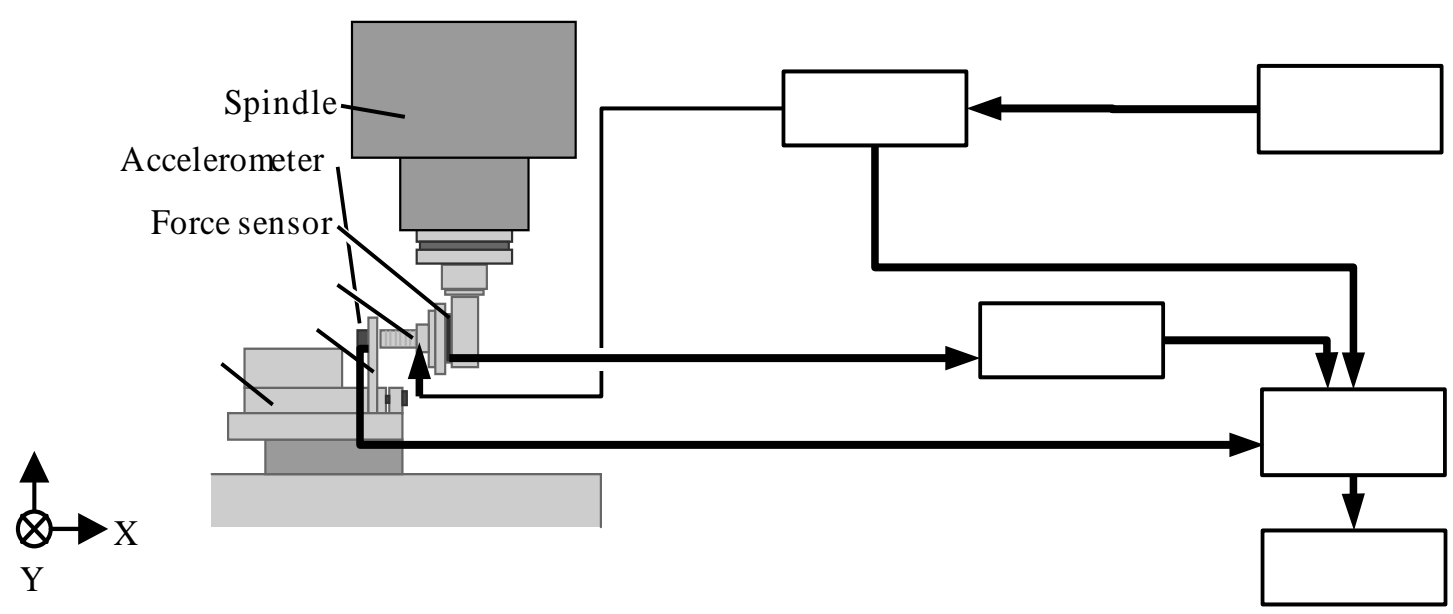

Fig.3 Experimental setup

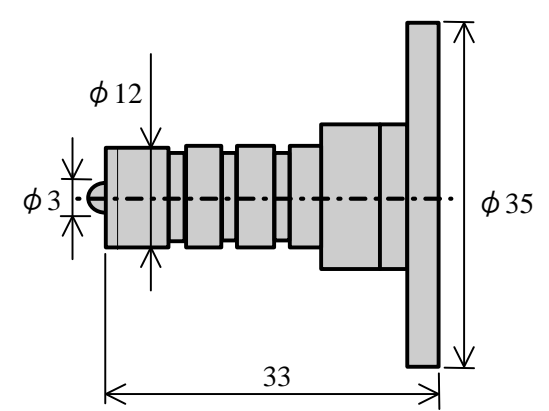

Fig. 4 Experimental piezoelectric actuator

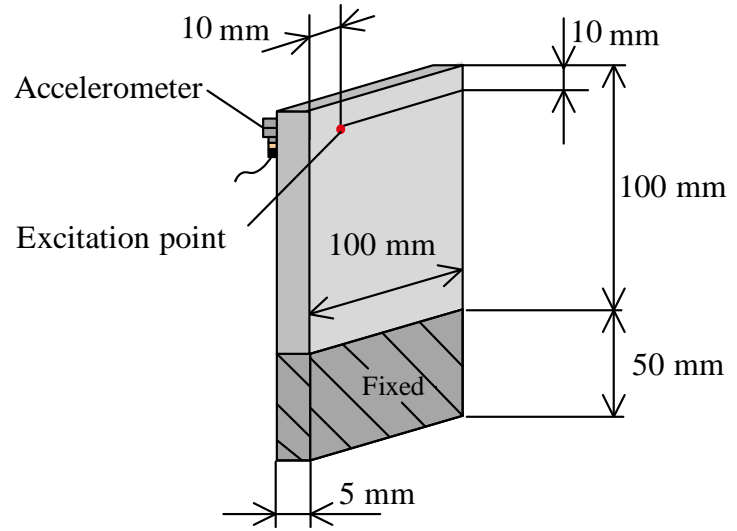

Fig. 5 Excitation and measurement positions

Figure 5 presents a schematic of the workpiece. The workpiece was fixed using a vise. The thickness of the workpiece was $5 \mathrm{~mm}$. The excitation point and measurement point of acceleration are depicted in Fig. 5.

For excitation using the PE method, a $120 \mathrm{~N}$ preload and swept sine command were provided to the piezoelectric actuator. The frequency of the swept sine command was increased from $1 \mathrm{~Hz}$ to $2200 \mathrm{~Hz}$ over $30 \mathrm{~s}$. The excitation force was measured by the force sensor (Kistler) in the shaker. The measured excitation force and workpiece acceleration were recorded using a data logger with a 24 bit analog-to-digital resolution. The sampling frequency was set to $15 \mathrm{kHz}$. Workpiece accelerance was calculated based on $\mathrm{H}_{1}$ estimation. Compliance was obtained by integrating the results. For the DSPE method, the measurement procedure was similar to that of the PE method. A monitor signal of the input voltage to the piezoelectric actuator was measured instead of the workpiece acceleration because the input voltage is used to obtain the resultant displacement using Eq.(2). The specifications of the measurement instruments are summarized in Table 1.

In the impact test, the workpiece was excited by an impulse hammer (PCB Piezotronics). The shaker was removed from the workpiece. Workpiece accelerance was 
Table 1 Specifications of measuring instruments

\begin{tabular}{lll}
\hline Force sensor & Measurement range & $26 \mathrm{kN}$ \\
& Sensitivity & $-3.8 \mathrm{pC} / \mathrm{N}$ \\
\hline Accelerometer & Measurement range & $\pm 10000 \mathrm{~m} / \mathrm{s}^{2}$ \\
& Sensitivity & $1 \mathrm{mV} /\left(\mathrm{m} / \mathrm{s}^{2}\right)$ \\
\hline Piezoelectric actuator & Size & $\varphi 12 \times 33 \mathrm{~mm}$ \\
& Maximum input voltage & $150 \mathrm{~V}$ \\
& Maximum displacement & Approximately $17 \mu \mathrm{m}$ \\
& Mechanical spring constant $k_{p}$ & $45.9 \mathrm{~N} / \mu \mathrm{m}$ \\
& Electromechanical coupling & $68 \%$ \\
& factor $\theta_{p}$ & \\
& Capacitance & $1.4 \mu \mathrm{F}$ \\
\hline
\end{tabular}
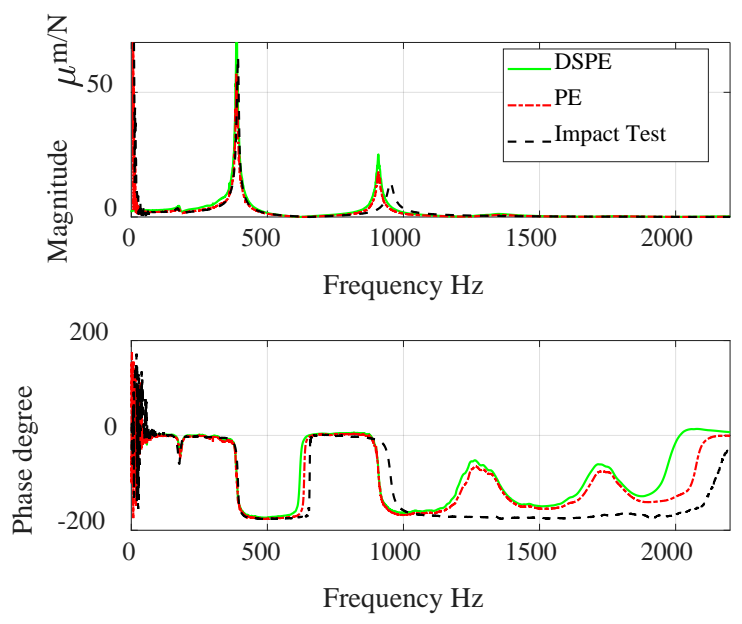

Fig. 6 Measured workpiece compliance

calculated based on $\mathrm{H}_{1}$ estimation. Compliance was obtained by integrating the results. The bandwidth of the measurement was set to $4000 \mathrm{~Hz}$ and the number of data points was 8192. The number of averaging was 5 .

\subsection{Comparison of compliance}

Fig. 6 presents a comparison of the compliance values obtained during the experiment. In the magnitude plot in Fig. 6, one peak can be observed at approximately $390 \mathrm{~Hz}$. This peak corresponds to the natural frequency of the bending mode of the workpiece. Another small peak is visible at approximately 900-950 Hz. This small peak corresponds to the torsional mode.

In the phase plot in Fig.6, the results by DSPE and PE methods are different from that by the impact test at approximately $1300 \mathrm{~Hz}$ and $1700 \mathrm{~Hz}$. These discrepancies are caused by the resonance of the shaker-spindle system. The bandwidth of the on-machine measurement system is limited by the compliance of the tool-workpiece loop. The influence of the shaker-spindle system compliance is discussed in Section 4. 


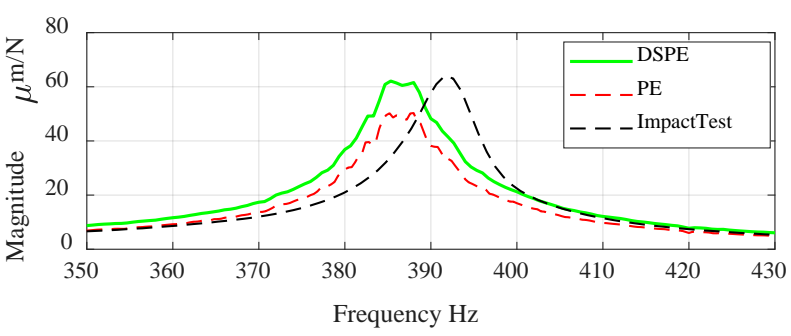

(a) First resonance peak

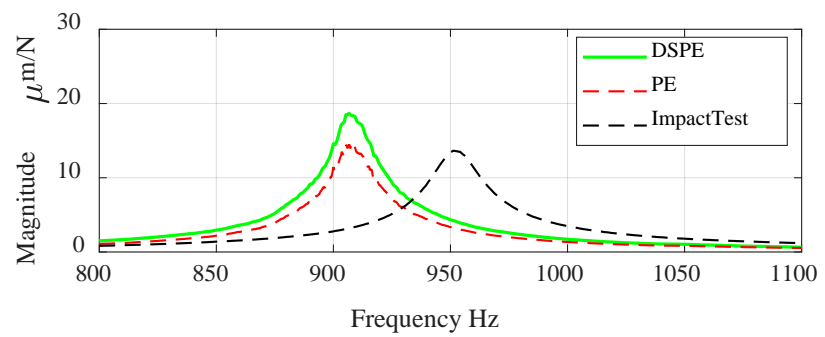

(b) Second resonance peak

Fig. 7 Magnified view of Fig. 6

Fig. 7 presents magnified views of magnitude around the natural frequency. The natural frequency measured by the DSPE method is similar to that measured by the PE method. When comparing the DSPE method to the impact test, the natural frequency by the impact test is higher than that by the DSPE method. The differences of the natural frequency are $10 \mathrm{~Hz}$ in the bending mode and $50 \mathrm{~Hz}$ in the torsional mode. Further investigation revealed that this natural frequency difference appears because the mass of the tip of the piezoelectric actuator acts as an additional mass [19]. A larger equivalent mass of a workpiece results in a smaller natural frequency difference. When the additional mass is less than $5 \%$ of the workpiece equivalent mass, the difference in natural frequency is less than $10 \mathrm{~Hz}$, which is negligible. The effect of the additional mass can be manually corrected in cases where the workpiece equivalent mass is small [21].

In the resonance shown in Fig.7(a) and (b), the magnitude by the DSPE method are $13 \%$ and $86 \%$ larger than those by the impact test, respectively. This magnitude difference can be caused by the low $\mathrm{S} / \mathrm{N}$ ratio in the force data. In the DSPE method, the excitation force depends on the workpiece compliance because the displacement amplitude of the piezoelectric actuator is almost constant over the entire frequency range. The measurement accuracy in force measurement is decreased at the natural frequency because the large workpiece compliance decreases the excitation force.

When the DSPE method is compared to the PE method, the magnitude of the DSPE method are 26\% and 38\% larger in the resonance shown in Fig.7(a) and (b). Also in the result shown in Fig.6, the magnitude of the DSPE method is approximately 30\% larger than that of the PE method over the entire frequency range. Because the force data is common in the DSPE and PE methods, this magnitude difference is caused by the estimation error of displacement. The parameter error of the displacement model is possible reason of the estimation error.

The experimental results show that the frequency dependency of the compliance and the resonance frequency can be evaluated using the DSPE method. The quantitative 


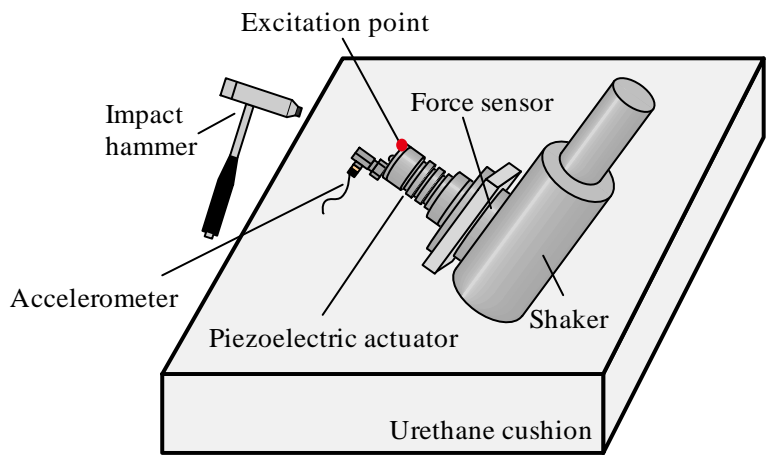

(a) Free-free condition

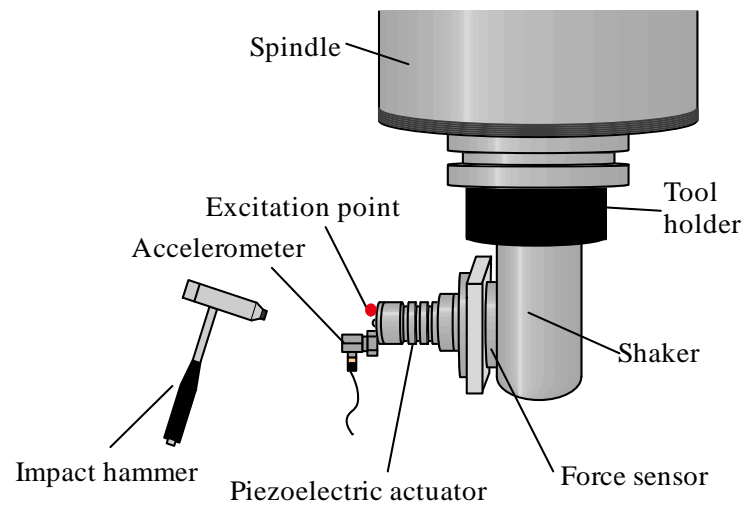

(b) Shaker attached on spindle

Fig. 8 Experimental setup in impact test

measurement accuracy of the compliance magnitude will be investigated and improved in future work.

\section{Influence of shaker-spindle system compliance}

As described in section 3.2, the tool-workpiece loop compliance influences the result by the DSPE method. In many cases, the compliance of the tool dominates the maximum loop compliance of vertical machining centers. The influence of compliance of the shaker-spindle system on the measurement using the DSPE method is investigated in this section.

\subsection{Experimental method}

Fig. 8 shows the experimental setup. The impact test of the shaker was conducted for free-free condition to obtain the dynamic stiffness of the shaker. The shaker was removed from the spindle and put on an urethane cushion. The impact test was also conducted when the shaker was attached on the spindle to obtain the dynamic stiffness of the shaker-spindle system. In both conditions, the tip of the piezoelectric actuator is excited using an impulse hammer. The acceleration in the excitation direction was measured using a 1-axis accelerometer attached near the excitation point. The accelerance was obtained from the measured excitation force and acceleration. The compliance was calculated by integration. The experimental condition is similar to that described in section 3.1. In this experiment, the sensitivity of the accelerometer is $10 \mathrm{mV} /\left(\mathrm{m} / \mathrm{s}^{2}\right)$.

\subsection{Experimental result}

Fig. 9 presents the compliance of the shaker for free-free condition. The highest resonance peak is observed at approximately $2300 \mathrm{~Hz}$. Fig. 10 presents the compliance of the shaker attached on the spindle. Three resonance peaks are observed at approximately $1200 \mathrm{~Hz}, 2350 \mathrm{~Hz}$ and $3300 \mathrm{~Hz}$. The second peak can be caused by the resonance of the shaker itself because the natural frequency is similar to that in Fig.9. The first and third peaks are caused by the resonance of the spindle or tool holder.

In Fig. 10, the magnitude is less than $0.06 \mu \mathrm{m} / \mathrm{N}$ in the frequency range of 70-1000 $\mathrm{Hz}$. The large magnitude observed in the frequency range of $0-70 \mathrm{~Hz}$ is caused typically by the integration of the noise in acceleration measurement. Thus, when the workpiece 

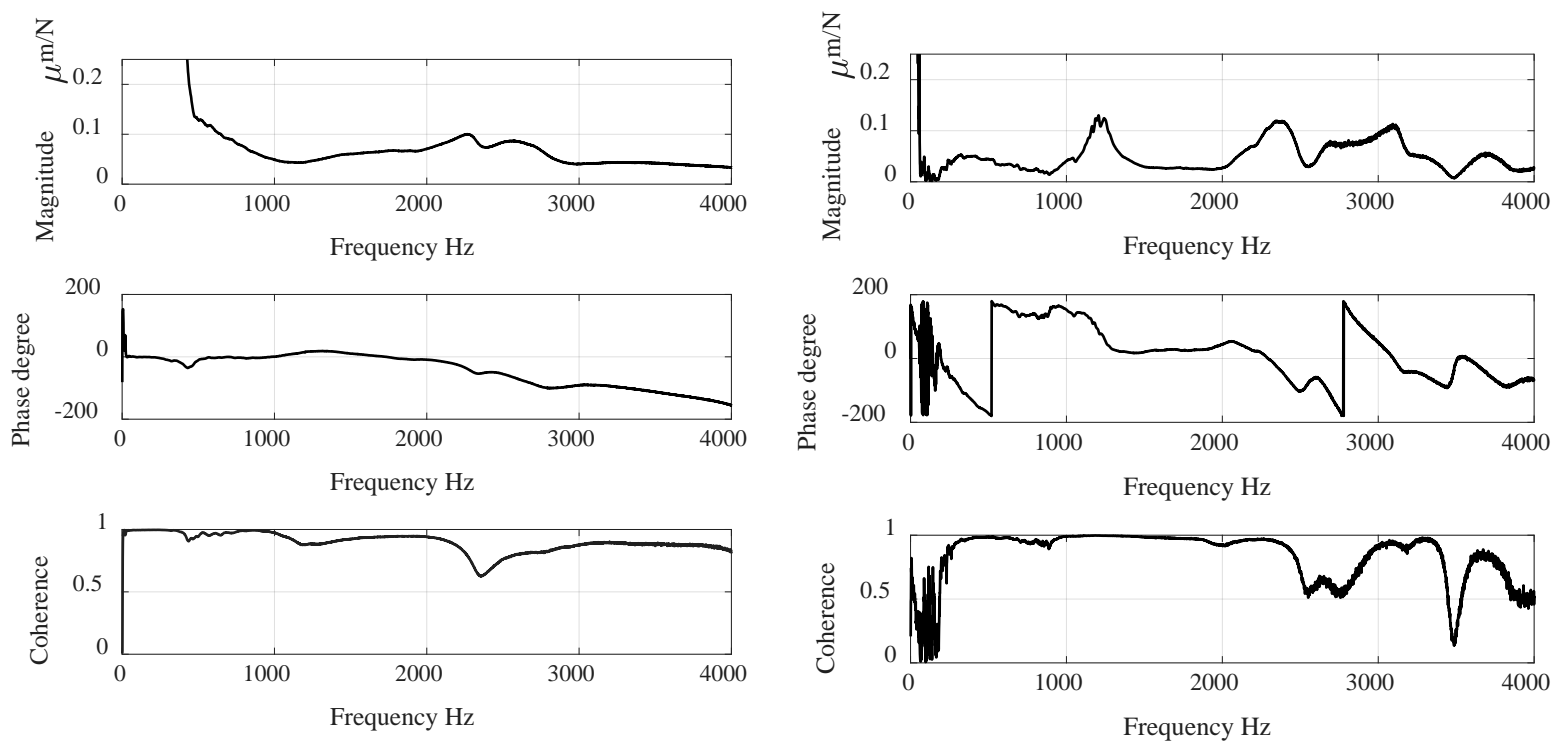

Fig. 9 Compliance of shaker in free-free condition

Fig. 10 Compliance of shaker attached on machine tool spindle

compliance is larger than $0.6 \mu \mathrm{m} / \mathrm{N}$, the influence of the dynamic stiffness of the shaker-spindle system is negligible. The $1000 \mathrm{~Hz}$ bandwidth is high enough for many workpieces. In the similar manner, the workpiece compliance should be larger than 1.3 $\mu \mathrm{m} / \mathrm{N}$ when the measurement bandwidth is increased to $4000 \mathrm{~Hz}$ because the magnitude shown in Fig. 10 is less than $0.13 \mu \mathrm{m} / \mathrm{N}$.

The required workpiece compliance depends on the machine because the tool-workpiece compliance depends on the machine type and size. In our previous investigation, the tool-workpiece compliance was less than $0.3 \mu \mathrm{m} / \mathrm{N}$ for two different vertical machining centers of medium size [22, 23]. Thus, the authors expect that the DSPE method can be applied for various vertical machining centers of medium size when the workpiece compliance is larger than $3 \mu \mathrm{m} / \mathrm{N}$.

\section{Cutting experiment}

For practical verification of the DSPE method, cutting experiments were conducted. Workpiece compliance was measured using the DSPE method. The vibration amplitude during cutting was compared to the measured compliance.

\subsection{Experimental method}

The experimental setup is presented in Fig. 11. The thin-walled workpiece presented in Fig. 12 was machined using an end mill. The workpiece material was carbon steel (JIS S50C). The vibration amplitude of the workpiece was measured by the accelerometer as the workpiece was excited by the cutting force. The spindle speed was varied to modify the tooth passing frequency, which represents the excitation frequency. A relationship between tooth passing frequency and vibration amplitude was obtained. The obtained relationship was compared to the workpiece compliance measured by the DSPE method. When the feed per tooth and axial depth of cut are constant, the variation in the vibration amplitude should correspond to the workpiece compliance, even if the 


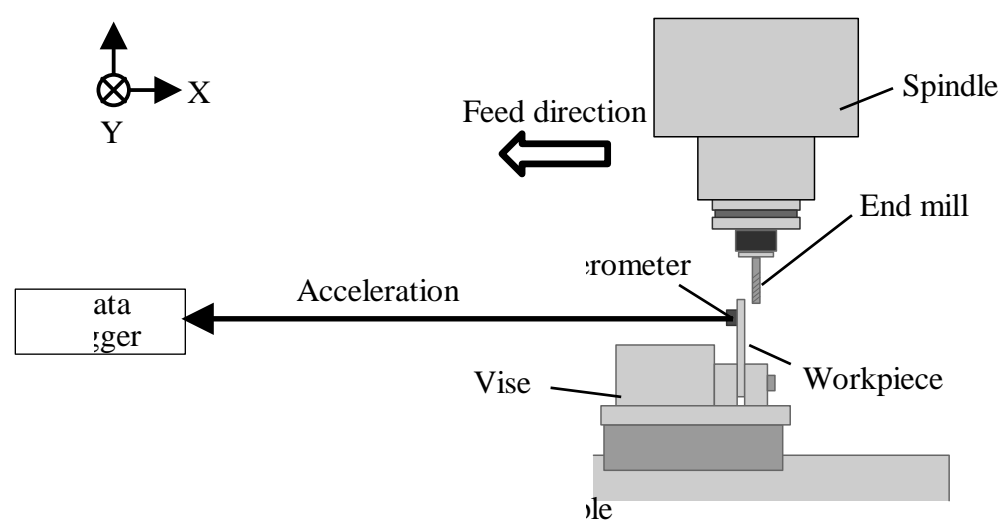

Fig. 11 Experimental setup for the cutting experiment

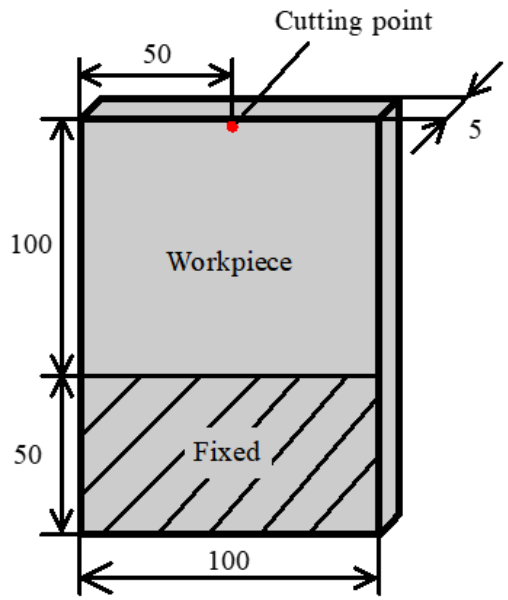

Fig. 12 Workpiece used for the cutting experiment

spindle speed changes. This is because the cutting force is theoretically constant when the influence of cutting speed on specific cutting force is small.

The accelerometer used in this experiment was a piezoelectric sensor with a sensitivity of $1 \mathrm{mV} /\left(\mathrm{m} / \mathrm{s}^{2}\right)$. The tool was a carbide square end mill with six teeth and a diameter of $6 \mathrm{~mm}$. The workpiece was fixed by a vise. The tool was attached to the spindle using a tool holder with a spring collet. The cutting conditions are listed in Table 2. The axial depth of cut was $0.1 \mathrm{~mm}$. Based on changes in the spindle speed, the feed rate was also changed to maintain a constant removal volume per tooth. The workpiece was replaced with a new piece for every trial.

\subsection{Experimental results}

The workpiece acceleration measured for case four are presented in Fig. 13. The number of teeth engaging the workpiece varied from one to three during machining because the machining process was a slotting operation. A schematic drawing of tooth engagement is presented in Fig. 14. To derive a relationship between tooth passing frequency and excitation frequency, we focused on the period when only one tooth engaged the workpiece. The amplitude of workpiece displacement for each tooth passing frequency was obtained in the frequency domain. The displacement was calculated from acceleration via integration. The relationship between amplitude and tooth passing frequency is presented in Fig. 15. The amplitude is maximized at $370 \mathrm{~Hz}$, which corresponds to case six. 
Table 2 Cutting conditions

\begin{tabular}{cccc}
\hline $\begin{array}{c}\text { Case } \\
\text { number }\end{array}$ & $\begin{array}{c}\text { Tooth passing } \\
\text { frequency } \\
(\mathrm{Hz})\end{array}$ & $\begin{array}{c}\text { Spindle } \\
\text { speed } \\
\left(\mathrm{min}^{-1}\right)\end{array}$ & $\begin{array}{c}\text { Feed rate } \\
(\mathrm{mm} / \mathrm{min})\end{array}$ \\
\hline 1 & 310 & 3100 & 176 \\
2 & 330 & 3300 & 188 \\
3 & 340 & 3400 & 194 \\
4 & 350 & 3500 & 199 \\
5 & 360 & 3600 & 205 \\
6 & 370 & 3700 & 211 \\
7 & 380 & 3800 & 216 \\
8 & 400 & 4000 & 227 \\
\hline
\end{tabular}

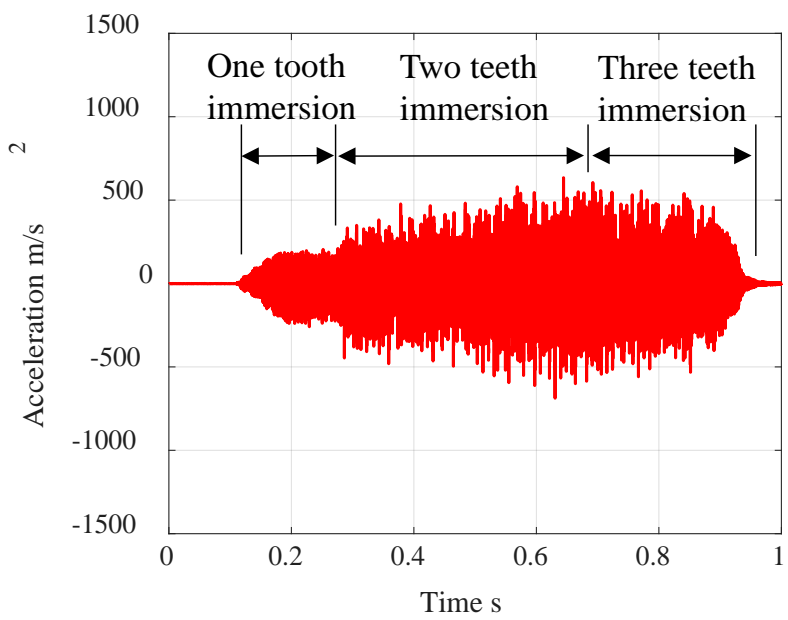

Fig. 13 Workpiece acceleration measured in case four

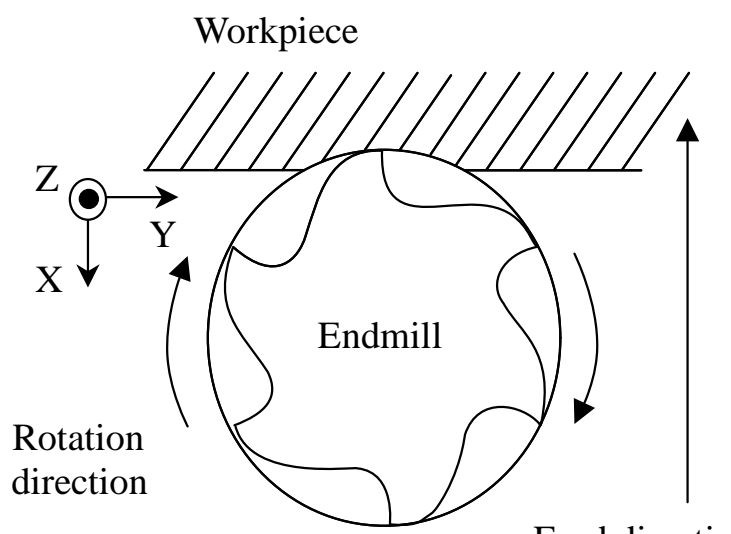

Feed direction

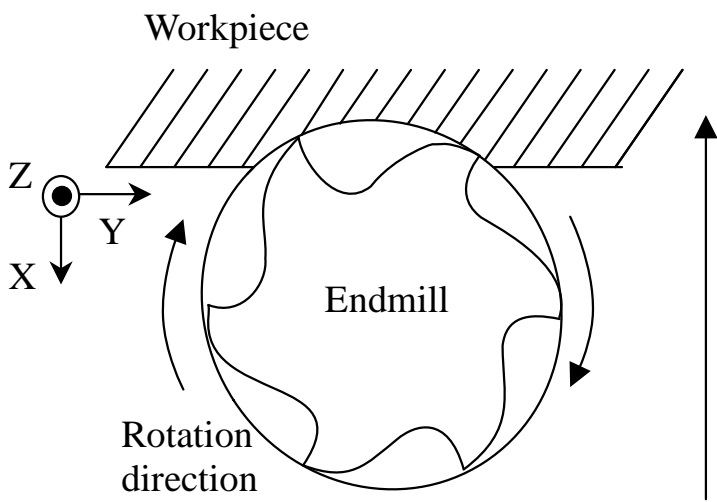

Feed direction

(a) One-tooth engagement

Fig. 14 Engagement between tool and workpiece 


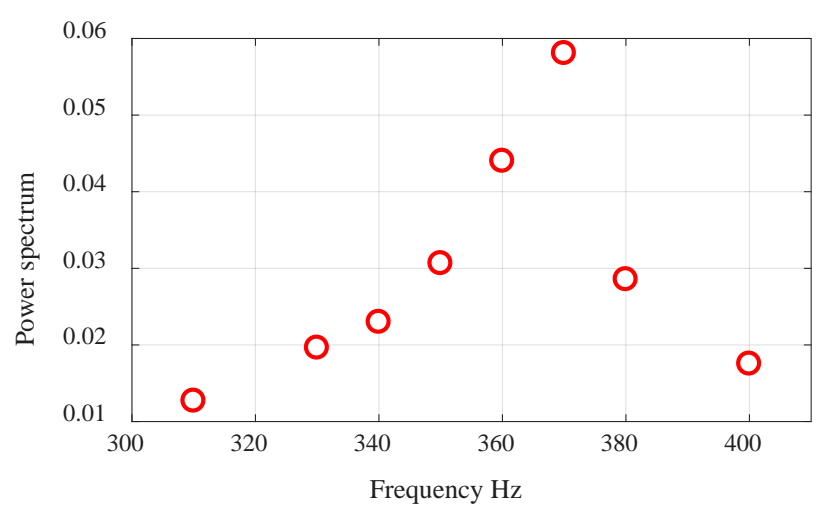

Fig. 15 Power spectrum of displacement
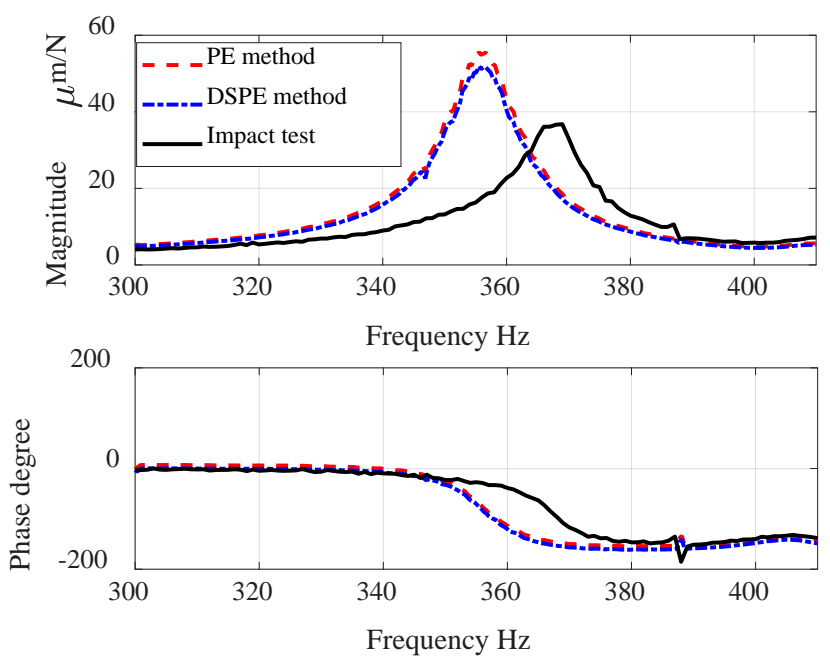

Fig. 16 Measured workpiece compliance

The workpiece compliances measured by the three methods are compared in Fig. 16. Resonance resulting from bending vibration can be observed in each result. The resonant frequency for the PE and DSPE methods is $355 \mathrm{~Hz}$, which is approximately $13 \mathrm{~Hz}$ lower than that for the impact test. This frequency difference is caused by the additional mass of the piezoelectric actuator, as described in Section 3.2. When Figs. 15 and 16 are compared, the variations in the vibration amplitude correspond to the measured compliances. This result indicates that the proposed on-machine measurement device can accurately evaluate the dynamic stiffness affecting vibration during the cutting process.

\section{Conclusion}

The DSPE method was proposed to measure the dynamic stiffness of thin-walled workpieces. The DSPE method does not require sensor setup on a workpiece because workpiece displacement is estimated from the excitation force and input voltage to a piezoelectric actuator. A displacement model for a piezoelectric actuator was also proposed. A measurement instrument was developed based on the DSPE method. The measurement accuracy of the DSPE method was verified by comparing the DSPE 
method to the conventional PE method and impact testing. The experimental results demonstrate that the variation of the compliance and the resonance frequency can be correctly obtained by the DSPE method. Although the DSPE method is almost comparable to the PE method, the quantitative measurement accuracy of the compliance magnitude should be improved. For the machine tool used in this study, when the measurement bandwidth is less than $1000 \mathrm{~Hz}$, the workpiece compliance should be larger than $0.6 \mu \mathrm{m} / \mathrm{N}$ to neglect the influence of the dynamic stiffness of the shaker-spindle system. When the measurement bandwidth is increased to $4000 \mathrm{~Hz}$, the workpiece compliance should be larger than $1.3 \mu \mathrm{m} / \mathrm{N}$. The experimental results demonstrate that the DSPE method can evaluate the dynamic stiffness affecting vibration during the cutting process.

\section{Acknowledgements}

This work was supported by KAKENHI(17K06078) and NSK-FAM (NSK Foundation for the Advancement of Mechatronics).

\section{References}

[1] J. Wang, S. Ibaraki, A. Matsubara, A cutting sequence optimization algorithm to reduce the workpiece, Precision Engineering 50 (2017) 506- 514.

[2] Y. Altintas, O. Tuysuz, M. Habibi, Z.L. Li, Virtual compensation of deflection errors in ball end milling of flexible blades, CIRP Annals - Manufacturing Technology 67 (2018) 365-368.

[3] Z. L. Li, L. M. Zhu, Compensation of deformation errors in five-axis flank milling of thin-walled parts via tool path optimization, Precision Engineering 55 (2019) 77- 87.

[4] J. Ma, D. Zhang, B. Wu, M. Luo, Y. Liu, Stability improvement and vibration suppression of the thin-walled workpiece in milling process via magnetorheological fluid flexible fixture, International Journal of Advanced Manufacturing Technology, 88 (2017) 1231-1242.

[5] K. Kolluru, D. Axinte, A. Becker, A solution for minimising vibrations in milling of thin walled casings by applying dampers to workpiece surface, CIRP AnnalsManufacturing Technology, 62 (2013) 415-418.

[6] K. Kolluru, D. Axinte, Novel ancillary device for minimizing machining vibrations in thin wall assemblies, International Journal of Machine Tools and Manufacture, 85 (2014) 79-86.

[7] E. Ozturk, A. Barrios, C. Sun, S. Rajabi, J. Munoa, Robotic assisted milling for increased productivity, CIRP Annals- Manufacturing Technology, 67 (2018) 427-430.

[8] L. R. Castro, P. Vieville, P. Lipinski, Correction of dynamic effects on force measurements made with piezoelectric dynamometers, International Journal of Machine Tools and Manufacture, 46 (2006) 1707-1715.

[9] N. Ameri, C. Grappasonni, G. Coppotelli, D. J. Ewins, Ground vibration tests of a helicopter structure using OMA techniques, Mechanical Systems and Signal Processing 35 (2013) 35-51. 
[10] É. L. Oliveira, N. M. M. Maia, A. G. Marto, R. G. A. da Silva, F. J. Afonso, A. Suleman, Modal characterization of composite flat plate models using piezoelectric transducers, Mechanical Systems and Signal Processing 79 (2016) 16-29.

[11] E. Korkmaz, B. Bediz, B. A. Gozen, O. B. Ozdoganlar, Dynamic characterization of multi-axis dynamometers, Precision Engineering 38 (2014) 148- 161.

[12] T. Sun, L. Qin, Y. Fu, J. Hou, Chatter stability of orthogonal turn-milling analyzed by complete discretization method, Precision Engineering 56 (2019) 87-95.

[13] M. A. Butt, Y. Yang, X. Pei, Q. Liu, Five-axis milling vibration attenuation of freeform thin-walled part by eddy current damping, Precision Engineering 51 (2018) 682- 690.

[14] J. Feng, M. Wan, T. Q. Gao, W. H. Zhang, Mechanism of process damping in milling of thin-walled workpiece, International Journal of Machine Tools and Manufacture, 134 (2018) 1-19.

[15] S. Seguy, G. Dessein, L. Arnaud, Surface roughness variation of thin wall milling, related to modal interactions, International Journal of Machine Tools and Manufacture, 48 (2008) 261-274.

[16] Y. Sun, S. Jiang, Predictive modeling of chatter stability considering force-induced deformation effect in milling thin-walled parts, International Journal of Machine Tools and Manufacture, 135 (2018) 38-52.

[17] Y. Yang, W. H. Zhang, Y. C. Ma, Min. Wan, Chatter prediction $f$ or the peripheral milling of thin-walled workpieces with curved surfaces, International Journal of Machine Tools and Manufacture, 109 (2016) 36-48.

[18] A. Jannifar, M. N. M. Zubir, S. N. Kazi, Development of a new driving impact system to be used in experimental modal analysis (EMA) under operational condition, Sensors and Actuators A 263 (2017) 398-414.

[19] T. Umezu, D. Kono, A. Matsubara, Evaluation of on-machine measuring method for dynamic stiffness of thin-walled workpieces, Procedia CIRP, 77 (2018) 34-37, open access.

[20] K. Yamada, H. Matsuhisa, H. Utsuno, K. Sawada, Optimum tuning of series and parallel LR circuits for passive vibration suppression using piezoelectric elements, Journal of Sound and Vibration, 329 (2010) 5036-5057.

[21] S. Bi, J. Ren, W. Wang, G. Zong, Elimination of transducer mass loading effects in shaker modal testing, Mechanical Systems and Signal Processing, 38 (2013) 265275.

[22] D. Kono, Y. Moriya, A. Matsubara, Influence of rotary axis on tool-workpiece loop compliance for five-axis machine tools, Precision Engineering, 49 (2017) 278-286.

[23] D. Kono, A. Matsubara, Investigation on direction dependency of tool-workpiece compliance of machine tool, Procedia CIRP, 46 (2016) 529-532, open access. 